\title{
Anti Bacterial and Anti Oxidant Activities of Evolvulus Alsinoides Linn
}

\author{
Nazanin Soudbakhsh Moghadam ${ }^{1}$, Anil Kumar H.V ${ }^{2}$, Laksmikanth. R.N ${ }^{3}$, \\ Muralidhar.S.Talkad ${ }^{4 *}$, Meghna Nagaraj ${ }^{5}$, Manasa D. $\mathrm{R}^{6}$ \\ ${ }^{1}$ Research Scholar, Kalinga University. Campus: Village - Kotni, Near Mantralay, Naya Raipur - 492101 \\ ${ }^{2}$ Dept of Environmental science \& Laboratory for Applied biological Sciences, DVS College of Arts and \\ Science, Shimoga, Karnataka, India \\ ${ }^{3}$ Department of Biotechnology /Applied Genetics. MS Ramaiah College of Arts, Science \& Commerce. \\ MSR Nagar. Bangalore - 560 054, India \\ ${ }^{4,5,6}$ P.G. Department of Biotechnology, R\&D Centre, Dayananda Sagar Institutions, Kumaraswamy Layout, \\ Bangalore-560078, India
}

\begin{abstract}
Plants are very important sources of potential useful raw materials as natural chemotherapeutic agents. Shankhpushpi is botanically termed as Evolvulus alsinoides; the extracts have exhibited antioxidant, anti-ulcer, and immunomodulatory activities. The present work is to investigate the invitro therapeutic potential activities of methanolic extract of whole plant of Evolvulus alsinoides on the antimicrobial activity against five clinical pathogenic bacterial strains viz., Staphylococcus aureus, Bacillus cereus, Escherichia coli, Klebshiella pneumonia and Salmonella typhii, using agar well diffusion assay and Anti oxidant activity using 1-1-Diphenyl2-picryl-hydrazyl (DPPH) radical. Extract inhibited $I C_{50}$ : 40.2. Total phenolic content: $28.4 \mathrm{mg} / \mathrm{ml} \&$ Total flavonoid content: $20.2 \mu \mathrm{g} / \mathrm{ml}$. Evolvulus alsinoides (MIC): $512.5 \mathrm{mg} / \mathrm{ml}$ possess 30 to $40 \%$ inhibition, the antibacterial activity of the herbal extracts was more pronounced on the gram-negative bacteria Klebshiella pneumonia than the gram-positive bacteria Staphylococcus aureus. The free radical scavenging activity of methanolic activity of whole plant of Evolvulus alsinoides increase in a concentration dependent manner, and posses statistically significance DPPH free radical scavenging \& Anti microbial activities
\end{abstract}

Keywords: Evolvulus alsinoides, total phenolic and flavonoid content, DPPH free radical Scavenging \& Anti microbial activities

\section{Introduction}

Medicinal herbs are a rich source of antimicrobial agents. A wide range of medicinal plant parts are used for extract as raw drugs and possess varied medicinal properties. ${ }^{1,2}$ Primitive people learned by trial and error to distinguish useful plants with beneficial effects from those that were toxic or non-active and also which combinations or processing methods had to be used to gain consistent and optimal results. ${ }^{3}$ In spite of the great advances observed in modern medicine in recent decades, plants still make an important contribution to health care $^{4}$ In comparison with modern medicine, herbal medicines cost less, are more often used to treat chronic diseases and the occurrence of undesirable side effects seems to be less frequent. Contrary to the synthetic drugs, antimicrobials of plant origin are not associated with side effects and have great therapeutic potential to heal many infectious diseases. ${ }^{5}$ Taking into consideration the large potential of plants as sources for antimicrobial drugs, many systematic investigations were taken into consideration and screened in different parts of the world. ${ }^{6,7}$

The importance of the reactive oxygen species (ROS) has attracted increasing attention over the last decade. Reactive oxygen species include free radicals such as super oxide anion radicals, hydroxyl radicals, non free radicals such as hydrogen peroxide and singlet oxygen, along with various forms of activated oxygen. They are involved in various physicochemical processes and disease such as aging, cancer and activity atherosclerosis. ${ }^{8}$

The preliminary phytochemical screening carried out in E. alsinoides contains some secondary metabolites such as glycosides, alkaloids, poly phenols, carbohydrates, amino acids and proteins, saponins, volatile oil, flavonoids and tannins. ${ }^{9}$ The plant contains alkaloids such as betaine, shankhapushpine, B-sitosterol and evolvine. Fresh plant contains volatile oil.

These compounds help brain stimulation and increase the ability to concentrate. Early phytochemical studies of this species resulted in the isolation and identification of chemical constituents such as triacontane, pentatriacontane.

Four unidentified alkaloids A, B, C and evolvine have also been described. The present study planned on Methanolic extract of whole plant of Evolvulus alsinoides for antioxidant potential and Anti microbial activities, which possess prominent immunomodulatory response and for treating various infectious diseases 


\section{(1) Plant materials and extraction}

\section{Materials And Methods}

The plant material was collected from the local rural area of Tumkur district in Karnataka state, India. The plant materials were identified and authenticated. The Plant material were air-dried and pulverized in course powder and was loaded in the Soxhlet apparatus for defating with petroleum ether and followed by extraction with methanol. The methanolic extract of Evolvulus alsinoides was subjected to fractionation and dry concentrated extract were used for the study

\section{(2) Analytical test for TLC}

Alkaloid analyses were done by using the Solvent system: Ethyl acetate: Formic Acid: Acetic Acid: Water - Ratio 50:5.5:5.5: 13.5, Yellow-Brown colored spots were detected in day-light and UV (256 nm) Flavonoid analyses were done by using the Solvent system: Chloroform: Methanol- Ratio 42.5: 7.5, Yellow colored spots in Day-light and UV.

\section{(3) Total Phenolic compounds}

The method (Slinkard K,, et al, 1977; Ragazzi and Veronese, 1973) downscaled to $1 \mathrm{~mL}$ final volume was followed to determine the amounts of total phenolics in the test samples. The test samples (each100/L) were mixed with $500 / \mathrm{L}$ of 1:10 Folin-Ciocalteau's reagent followed by the addition of $\mathrm{Na}_{2} \mathrm{CO}_{3}(400 / \mathrm{L}$, $7.5 \%) .{ }^{10,11}$ After incubating the reaction mixture at $24{ }^{\circ} \mathrm{C}$ for $2 \mathrm{~h}$, the absorbance at $765 \mathrm{~nm}$ was recorded. Gallic acid monohydrate was used as the standard. The total phenolic contents as gallic acid equivalents ( $\mu \mathrm{g}$ of GAE)/mg dry weight of the samples

\section{(4) Total flavanoid content}

The determination of the total flavanoid content (TFC) was carried out, briefly, $2.5 \mathrm{ml}$ of each extract solution was mixed with $2.5 \mathrm{ml} \mathrm{AlCl} 3$ reagent in ethanol $90 \%$ and allowed to stand for $40 \mathrm{~min}$ at room temperature. After that, the absorbance of the mixture at $415 \mathrm{~nm}$ was measured with a SHIMADZU Multispect1501 spectrophotometer. ${ }^{12}$

Ethanol $90 \%(2.5 \mathrm{ml})$ plus sample solution $(2.5 \mathrm{ml})$ was used as a blank. Rutin was used as a reference compound. The TFC for each extract [as $\mu \mathrm{g}$ rutin equivalents (RE) / $\mathrm{mg}$ of extract] was determined on the basis of the linear calibration curve of rutin (absorbance versus rutin concentration)

\section{(5) DPPH free radicals scavenging activity}

The free radical scavenging activity of the different fractions of Evolvulus alsinoides was measured using DPPH, $1 \mathrm{ml}$ of each fraction of Evolvulus alsinoides and the reference compound in various concentration $(50,100,250 \& 500 \mu \mathrm{g} / \mathrm{ml})$ was added to $1 \mathrm{ml}$ of $0.1 \mathrm{mM}$ solution of DPPH in methanol. After $30 \mathrm{~min}$., absorbance was measured at $517 \mathrm{~nm}$ using spectrophotometer. $0.01 \mathrm{mM}$ solution of DPPH in methanol was used as control, whereas Quercetin was used as reference material. All tests were performed in triplicate. Percentage inhibition was calculated by using following formula. ${ }^{13}$

$\%$ Inhibition $=$ control absorbance- test absorbance

\section{Control absorbance}

\section{(6) Anti bacterial Activity:}

Antibacterial activity of methanolic extract of Evolvulus alsinoides against different test organism was determined using a modified Kirby-Bauer disc diffusion method. ${ }^{14}$

Briefly, $100 \mu \mathrm{l}$ of the test bacteria were grown in $10 \mathrm{ml}$ of fresh media until they reached a count of approximately $10^{8}$ cells $/ \mathrm{ml}$. $100 \mu \mathrm{l}$ of the microbial suspension was spread onto nutrient agar plates.

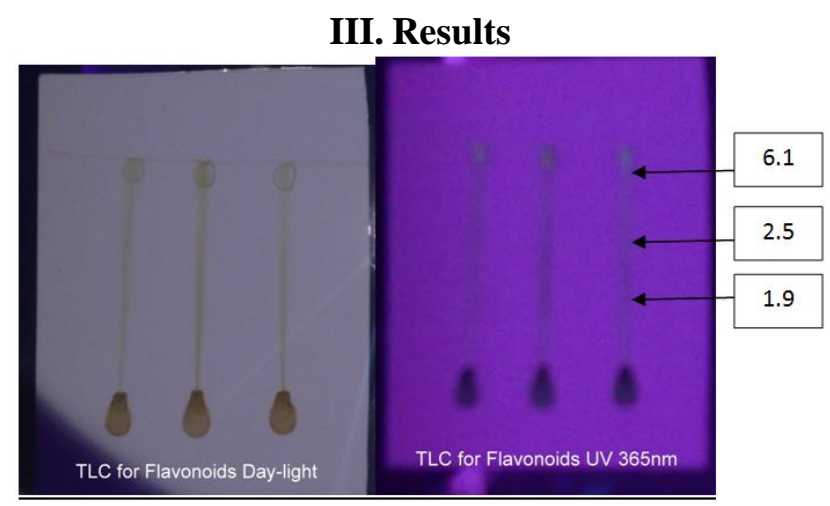




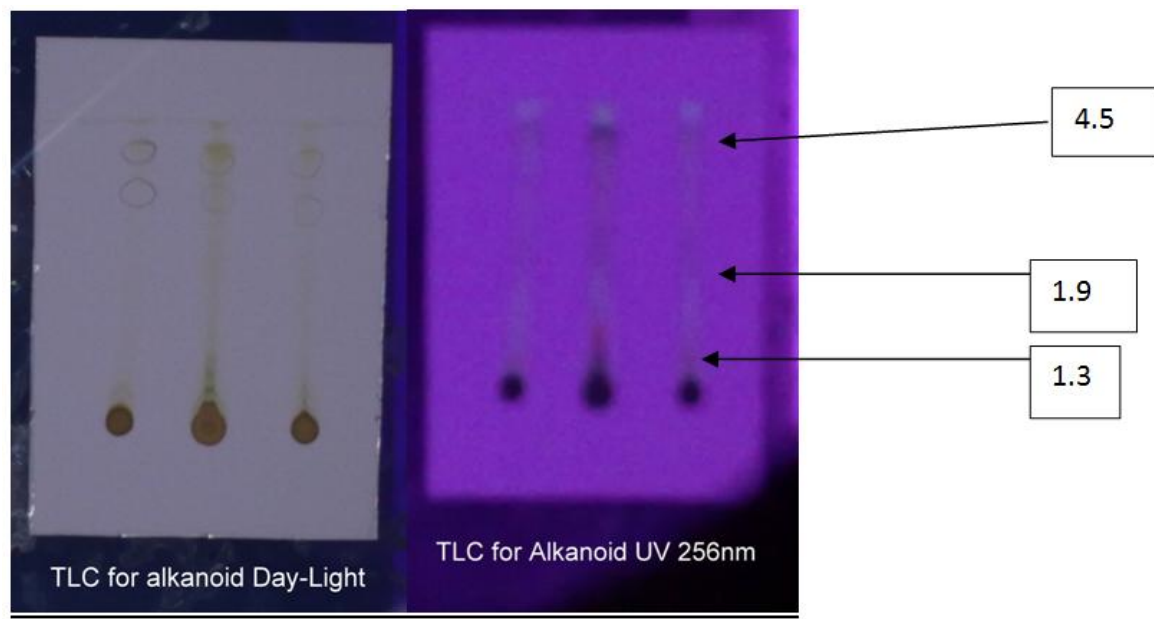

Fig: 1- TLC analysis

Table: 1. Anti oxidant potential of Methanolic extracts of E. alsinoides

\begin{tabular}{|c|c|c|c|}
\hline Plant material & TPC $(\mathbf{m g} / \mathbf{g})$ & TFC $(\boldsymbol{\mu g} / \mathbf{m g})$ & DPPH $\left(\mathbf{I C}_{\mathbf{5 0}}\right)$ \\
\hline Evolvulous alsinoides & $28.4 \pm 0.128$ & $20.2 \pm 0.212$ & $40.2 \pm 0.21$ \\
\hline
\end{tabular}

Note: TPC: Total Phenolic compounds. TFC: Total flavanoid content DPPH: free radicals scavenging activity (Anti oxidant activity).

Table: 2. The Minimum Inhibitory Concentrations of Methanolic extracts of E. alsinoides on Bacterial isolates

\begin{tabular}{|c|c|c|c|}
\hline SERIAL NO & ISOLATES & MTCC. No & MIC \\
\hline 1 & Bacillus cereus & 1305 & 512.5 \\
\hline 2 & Staphylococcus aureus & 3160 & 512.5 \\
\hline 3 & Klebshiella pneumonia & 39 & 32 \\
\hline 4 & Escherichia coli & 443 & 64 \\
\hline 5 & Salmonella typhii & 1254 & 16 \\
\hline
\end{tabular}

Table: 3. The Antibacterial Activities of the Methanolic extracts of E. Alsinoides on Bacterial strains

\begin{tabular}{|c|c|c|c|c|c|}
\hline \multirow{2}{*}{ Conc. $\mathbf{m g} / \mathbf{m l}$} & \multicolumn{5}{|c|}{ Zone of Inhibition (mm) of Bacterial Isolates } \\
\cline { 2 - 6 } & B. cereus & S. aureus & K. pneumonia & E. coli & S. typhi \\
\hline 512.5 & 08 & 05 & 34 & 23 & 24 \\
\hline 256 & 00 & 00 & 30 & 18 & 21 \\
\hline 128 & 00 & 00 & 26 & 12 & 16 \\
\hline 64 & 00 & 00 & 24 & 08 & 10 \\
\hline
\end{tabular}

The result of antibacterial activity of methanolic extract of Evolvulus alsinoides against different test organism have been tabulated in table -2 and 3 .

At a concentration of $512.5 \mathrm{mg} / \mathrm{ml}$, the highest zone of clearance was obtained from methanol extract against Klebsiella pnuemoniae with a diameter of $34 \mathrm{~mm}$. This was followed by Salmonella typhi $(24 \mathrm{~mm})$ and Escherichia coli $(23 \mathrm{~mm})$ respectively. The lowest zone of inhibition at this concentration was $5 \mathrm{~mm}$ against Staphylococcus aureus.

\section{Discussions}

The TLC analysis conducted in this experiment shows the presence of few alkaloids and flavonoids in the methanolic extract of Evolvulus alsinoides (table -1). This plant is used in Asia, Africa, and Philippines to cure fever, cough, cold, venereal disease, azoospermia, adenitis, and dementia, nootropic and anti inflammatory activity reported its use in the treatment neurodegenerative disease asthma and amnesia. ${ }^{15}, 16$ Pre- clinical researches has justified its ancient claim's brain tonic. ${ }^{15}$ Several other uses reported for this plant include its ability to boost memory and improve intellect, immunomodulatory, adaptogenetic as well as antioxidant properties. ${ }^{17}$ Plant phenolics constitute one of the major groups of compounds responsible for antioxidant behavior, as well as for antimicrobial effects. 
Flavonoids, this diverse and widespread group of natural compounds are the most important natural phenolics. They possess a broad spectrum of biological activities, including radical scavenging properties and antibacterial effect (table -1).The study plant E. alsinoides contains alkaloids: betaine, shankhapushpine and evolvine. Fresh plant contains volatile oil. It also contains a yellow neutral fat, an organic acid and saline substances.

Scopoletin, scopolin, umbelliferone, 2-methyl-1,2,3,4-Hydrophobic molecules can pass through cell wall of gram-positive bacteria easier than the gram- negative bacteria because cell wall of the gram- positive bacteria contained only peptidoglycan (table-2,3). ${ }^{18,19}$ These results agree with those reported that the antimicrobial effects of essential oil constituents are dependent on their hydrophobicity. ${ }^{20}$

\section{Conclusion}

The results revealed that the methanolic extract of Evolvulus alsinoides are potent antimicrobials against for all the microorganisms studied, since the plant extracts were rich in Alkaloid and flavonoids, it is indeed possess potent antioxidant activities

\section{References}

[1] Gisesa, W.N.O. An Ethnopharmacological investigation of plants used by Abagusii traditional medical practitioners, PhD Thesis, School of Pure and Applied Sciences, Kenyatta University. 2004.

[2] Egwaikhide, P.A., Gimba, C.E. Analysis of the phytochemical content and anti-microbial activity of Plectranthus glandulosis whole plant. Middle-East J. Sci. Res. 2(3-4), 2007, 135- 138

[3] Jagessar, R.C., Mars, A., Gomes, G. Selective Antimicrobial properties of Phyllanthus acidus leaf extract against Candida albicans, Escherichia coli and Staphylococcus aureus using stokes disc diffusion, well diffusion, streak plate and a dilution method. Nature Sci. 6(2), 2008, 24-38

[4] Ravikumar, S., Selvan, G.P., Gracelin, A.A. Antimicrobial activity of medicinal plants along Kanyakumari Coast, Tamil Nadu, India. Afr. J. Basic Appl. Sci. 2(5- 6), 2010, 153-157.

[5] Jagessar, R.C., Mohamed, A., Gomes, G. Antibacterial and antifungal activity of leaf extracts of Luffa operculata, vs. Peltophorum Pterocarpum, against Candida albicans, Staphylococcus aureus and Escherichia coli. Nature Sci., 5(4), 2007, 81-93.

[6] Nascimento, G., Locatelli, G.F., Freitas, P.C., Silva, G.L. Antibacterial activity of plant extracts and phytochemicals on antibiotic resistance bacteria. Bras. J. Microbiol, 31, 2000, 247- 256.

[7] Ahmad, I., Beg, A.Z. Antibacterial and phytochemical studies on 45 Indian medicinal Plants against multiple drug resistant human pathogens. J. Ethnopharma, 74, 200, 1113- 123.

[8] Zuhaib Zafar, Muralidhar. S. Talkad, Chinmay Bandopadhyay, Madhurima Sinha, Jinnia Sarkhel. Antioxidant Activity of Five Selective Medicinal Plants. African Journal of Scientific Research, Vol. 2, No. 1, 2011, 126 - 147.

[9] Omogbai BA, Ze FA. Phytochemical screening and susceptibility of bacteria pathogens to extracts of Evolvulus alsinoides. Sci World J, 6, 2011, 5-8.

[10] Slinkard K, Singleton VL. Total phenol analyses: Automation and comparison with manual methods. American J Enol Viticulture, 28, 1977, 49-55.

[11] Ragazzi E, Veronese G. Quantitative analysis of phenolic compounds after thin-layer chromatographic separation. $J$ Chromatograph, Mar 28; 77(2), 1973, 369-75.

[12] Nickavar B, Kamalinejad M, Haj-Yahya M and Shafaghi B. Comparison of the free radical scavenging activity of six Iranian Achillea species. Pharm. Biol, 44, 2006, 208-212.

[13] Blois MS. Antioxidant determination by the use of stable free radical. Nature, 29, 1958, 1199-200.

[14] Bauer, AW, Kirby, WM, Sherris, JC and Turck, M. Antibiotic susceptibility testing by a standardized single disk method, American Journal of Clinical Pathology, 45, 1966, 493-496.

[15] Singh, A. Review of ethano medicinal use and pharmacology of Evolvulus alsinoides Linn. Ethanobot. Leaflets, 12, 2008, 734-740.

[16] Goyal, P.R., Singh, K.P. Evolvulus alsinoides Linn. A medicinal herb. Int. J. Mendel, 22(3-4), 2005, 124-125.

[17] Sethiya, N.K., Nahata, A., Dixit, V.K., Mishra, S.H. Shankhpushphi: cognition boosting ayurvedic medicine- An update. J. Chinese Integrat. Med, 7, 2009, 1001-22.

[18] Nikaido, H., Vaare, M. Molecular basis of bacteria outer membrane permeability. Microbiol. Rev, 49, 1985 , 1- 32.

[19] Lambert, R.J.W., Skandamis, P.N., Coote, P.J., Nychas, G.J.E. A study of the minimum inhibitory concentration and mode of action of oregano essential oil, thymol and Carvacrol. J. Appl. Microbiol, 91(3), 2001, 453 - 462.

[20] Lan-Ciotti, R., Gianotti, A., Patngnani, N., Belleti, N., Guerzoni, M.F., Gardini, F. Use of natural aroma compounds to improve shelf-life of minimally processed fruits. Trends Food Sci. Technol, 15, 2004, 201-208. 